\title{
An international benchmark study of K-12 computer science education in schools
}

\author{
Katrina Falkner \\ University of Adelaide \\ Sue Sentance \\ Raspberry Pi Foundation \\ Rebecca Vivian \\ University of Adelaide
}

See next page for additional authors

Follow this and additional works at: https://arrow.tudublin.ie/ittscicon

Part of the Computer Sciences Commons, and the International and Comparative Education

\section{Commons}

\section{Recommended Citation}

Katrina Falkner, Sue Sentance, Rebecca Vivian, Sarah Barksdale, Leonard Busuttil, Elizabeth Cole, Christine Liebe, Francesco Maiorana, Monica M. McGill, and Keith Quille. 2019. An International Benchmark Study of K-12 Computer Science Education in Schools. In Proceedings of the 2019 ACM Conference on Innovation and Technology in Computer Science Education (ITiCSE '19). Association for Computing Machinery, New York, NY, USA, 257-258. DOI: 10.1145/3304221.3325535

This Conference Paper is brought to you for free and open access by the School of Science and Computing at ARROW@TU Dublin. It has been accepted for inclusion in Conference Papers by an authorized administrator of ARROW@TU Dublin. For more information, please contact arrow.admin@tudublin.ie, aisling.coyne@tudublin.ie,gerard.connolly@tudublin.ie. 


\section{Authors}

Katrina Falkner, Sue Sentance, Rebecca Vivian, Sarah Barksdale, Leonard Busuttil, Elizabeth Cole, Christine Liebe, Francesco Maiorana, Monica M. McGill, and Keith Quille 


\section{An International Benchmark Study of K-12 Computer Science Education in Schools}

\author{
Katrina Falkner* \\ School of Computer Science \\ The University of Adelaide \\ Adelaide, South Australia, Australia \\ katrina.falkner@adelaide.edu.au \\ Sarah Barksdale \\ Department of Curriculum and \\ Instruction \\ University of Minnesota \\ Minneapolis, Minnesota, USA \\ barks016@umn.edu \\ Christine Liebe \\ Lotus Education Institute \\ Parker, Colorado, USA \\ clynnliebe@gmail.com
}

\author{
Sue Sentance* \\ Raspberry Pi Foundation \\ Cambridge, England, UK \\ sue@raspberrypi.org
}
Leonard Busuttil
Department of Technology and
Entrepreneurship Education
University of Malta
Msida, Malta
leonard.busuttil@um.edu.mt
Francesco Maiorana
Department of Education
University of Catania
Catania, Italy
fmaioran@gmail.com
Keith Quille
Department of Computing
Technological University Dublin
Tallaght, Dublin, Ireland
Keith.Quille@it-tallaght.ie

\author{
Rebecca Vivian* \\ School of Computer Science \\ The University of Adelaide \\ Adelaide, South Australia, Australia \\ rebecca.vivian@adelaide.edu.au \\ Elizabeth Cole \\ School of Computer Science \\ University of Glasgow \\ Glasgow, UK \\ e.cole.2@research.gla.ac.uk
}

Monica M. McGill

Faculty of Computer Science

Knox College

Galesburg, Illinois , USA

mmmcgill@knox.edu

\begin{abstract}
There has been a growing interest and increase in work shared about national K-12 Computer Science Education (CSED) curriculum and implementation efforts around the world. Much of this work focuses on curriculum analysis, country reports, experience reports and case studies.

The K-12 CSED community would benefit from an international strategic effort to compare, contrast and monitor K-12 CSED over time, across multiple countries and regions, to understand pedagogy, practice, resources and experiences from the perspective of teachers working in classrooms. Furthermore, there is a need for validated and robust instruments that can support comparable investigations into the current state of K-12 CSED in schools around the world.

Through a collaborative effort, this Working Group will develop a validated teacher survey instrument and collect data about CSED implementation and practice in $\mathrm{K}-12$ classrooms. The authors will

${ }^{*}$ Co-Leader

Permission to make digital or hard copies of part or all of this work for personal or classroom use is granted without fee provided that copies are not made or distributed for profit or commercial advantage and that copies bear this notice and the full citation on the first page. Copyrights for third-party components of this work must be honored.

For all other uses, contact the owner/author(s)

ITiCSE '19, fuly 15-17, 2019, Aberdeen, Scotland Uk

(C) 2019 Copyright held by the owner/author(s).

ACM ISBN 978-1-4503-6301-3/19/07.

https://doi.org/10.1145/3304221.3325535
\end{abstract}

pilot the survey with K-12 teacher cohorts and analyse, compare and contrast survey findings across countries.

\section{CCS CONCEPTS}

- Social and professional topics $\rightarrow$ Computing education; $K$ 12 education; Adult education;

\section{KEYWORDS}

ITiCSE Working Group, K-12, Computer Science Education, Informatics Education, Schools, Survey

\section{ACM Reference Format:}

Katrina Falkner, Sue Sentance*, Rebecca Vivian*, Sarah Barksdale, Leonard Busuttil, Elizabeth Cole, Christine Liebe, Francesco Maiorana, Monica M. McGill, and Keith Quille. 2019. An International Benchmark Study of K-12 Computer Science Education in Schools. In Innovation and Technology in Computer Science Education (ITiCSE '19), Fuly 15-17, 2019, Aberdeen, Scotland Uk. ACM, New York, NY, USA, 2 pages. https://doi.org/10.1145/3304221. 3325535

\section{RELATED WORK}

A number of country and regional reports have been produced, detailing K-12 CSED curriculum and initiatives across Europe [1, 7] and the UK $[15,16]$. The International Conference on Informatics in Schools (ISSEP) have also welcomed country reports, resulting in publications about the state of K-12 CSED in the Unites States (US) 
[8], Wales [12] and Poland [14], among others. The ACM Transactions on Computing Education (TOCE) dedicated two volumes for a special issue that covered a range of countries as case studies in K-12 CSED (see Vol. 14, no. 2, 2014) [9] and increasingly researchers have published works about their country curricula and/or initiatives, including in France [5], the Netherlands [2], Australia [6] and England [4], to name a few. Researchers have also performed comprehensive curriculum analysis across countries and resources to identify the emergence of common K-12 CSED topics and concepts to inform future curriculum developments and research [3, 17].

Related to this Working Group topic, in 2011 a Group [11] undertook the process of collecting and evaluating research findings about secondary CSED from different countries, and in the process developed a category system (Darmstadt Model) to support future research activities and comparison of results across regional and national boundaries. Expanding this work, a Working Group applied the Darmstadt Model to analyse, compare and extract insights from the articles published within two K-12 CSED special issues for TOCE [10]. This work sought to understand CSED topics taught in schools, goals and competencies, programming languages and tools adopted, assessment practices and teacher training, however, the authors acknowledged that a limitation of the study was that it was restricted to the analysis of selected journal publications.

In 2013, a Working Group formed to investigate trends of CS as a subject in schools by inviting CSED and teaching professionals worldwide to complete an online questionnaire about the current state of K-12 CSED in their country [13]. Experts from 22 countries responded, addressing CSED topics and goals covered across K-12 as well as teaching methods, however, a limitation being that results were based on a small group of experts.

Prior work has set a strong foundation for understanding the state of K-12 CSED curriculum and implementation efforts, however, there is an opportunity to further expand this work to focus on what K-12 teachers are doing in classrooms. There is also a need to develop instruments that are robust and reliable for use in longitudinal, multinational studies for comparisons across countries.

\section{OBJECTIVES}

The broad objectives of the Working Group are:

- To build an international research collaboration and strategy for investigating K-12 CSED in schools.

- To initiate a scalable, collective effort for a deeper investigation into what is happening in schools, based on the experiences of educators in classrooms.

- To develop an open source teacher survey instrument that can be implemented across countries.

This Working Group will build on prior work to a develop a validated instrument for surveying K-12 teachers about their experiences and approaches to CSED implementation in the classroom, including demographics, self-efficacy, teaching methods, experiences, use of resources and curriculum topics implemented.

The Group will review and draw on earlier work to guide the development of a validated and reliable instrument that can transcend boundaries and be used for consistent, ongoing data collection. The authors will pilot the survey with K-12 teacher cohorts in their locations and the group will collectively analyse, compare and contrast the survey findings. The report will describe the survey instrument and present the survey findings. The group will make the survey instrument available as open-source.

\section{REFERENCES}

[1] Anja Balanskat and Katja Engelhardt. 2014. Computing our future Computer programming and coding - Priorities, school curricula and initiatives across Europe. Technical Report. https://doi.org/10.1111/j.1465-7295.200

[2] Erik Barendsen, NataÅąa Grgurina, and Jos Tolboom. 2016. A new informatics curriculum for secondary education in The Netherlands. In Lecture Notes in Computer Science (including subseries Lecture Notes in Artificial Intelligence and Lecture Notes in Bioinformatics). https://doi.org/10.1007/978-3-319-46747-4\{_\}9

[3] Erik Barendsen, Linda Mannila, Barbara Demo, NataÅąa Grgurina, Cruz Izu, Claudio Mirolo, Sue Sentance, Amber Settle, and GabrielÄŮ Stupurienè. 2015. Concepts in K-9 Computer Science Education. In Proceedings of the 2015 ITiCSE on Working Group Reports - ITICSE-WGR '15. https://doi.org/10.1145/2858796. 2858800

[4] N Brown, M Kölling, T Crick, S Peyton Jones, S Humphreys, and S Sentance. 2013. Bringing computer science back into schools: lessons from the UK. In 44th ACM technical symposium on Computer Science education. ACM, Denver, Colorado, USA, 269-274.

[5] Vanea Chiprianov and Laurent Gallon. 2016. Introducing Computational Thinking to K-5 in a French Context. In Proceedings of the 2016 ACM Conference on Innovation and Technology in Computer Science Education - ITiCSE '16. https: //doi.org/10.1145/2899415.2899439

[6] Katrina Falkner and Rebecca Vivian. 2015. A review of Computer Science resources for learning and teaching with K-12 computing curricula: an Australian case study. Computer Science Education 25, 4 (2015), 390-429. https: //doi.org/10.1080/08993408.2016.1140410

[7] W Gander, A Petit, G Berry, B Demo, J Vahrenhold, A McGettrick, R Boyle, M Drechsler, A Mendelson, C Stephenson, C Ghezzi, and B Meyer. 2013. Informatics Education: Europe Cannot Afford to Miss the Boat. Technical Report. Association for Computing Machinery \&, Joint Informatics Europe ACM Europe Working Group on Informatics Education, New York. 1-21 pages.

[8] Hai Hong, Jennifer Wang, and Sepehr Hejazi Moghadam. 2016. K-12 computer science education across the U.S.. In Lecture Notes in Computer Science (including subseries Lecture Notes in Artificial Intelligence and Lecture Notes in Bioinformatics). https://doi.org/10.1007/978-3-319-46747-4\{_\}12

[9] Peter Hubwieser, Michal Armoni, and Michail N. Giannakos. 2015. How to Implement Rigorous Computer Science Education in K-12 Schools? Some Answers and Many Questions. ACM Transactions on Computing Education (2015). https://doi.org/10.1145/2729983

[10] Peter Hubwieser, Michail N. Giannakos, Marc Berges, Torsten Brinda, Ira Diethelm, Johannes Magenheim, Yogendra Pal, Jana Jackova, and Egle Jasute. 2015. A Global Snapshot of Computer Science Education in K-12 Schools. In ITiCSE Working Group Reports. ACM, Vilnius, Lithuani, 65-83. https://doi.org/10.1145/ 2858796.2858799

[11] Peter Hubwieser, Sigrid Schubert, Michal Armoni, Torsten Brinda, Valentina Dagiene, Ira Diethelm, Michail N. Giannakos, Maria Knobelsdorf, Johannes Magenheim, and Roland Mittermeir. 2011. Computer science/informatics in secondary education. In Proceedings of the 16th annual conference reports on Innovation and technology in computer science education - working group reports ITiCSE-WGR '11. https://doi.org/10.1145/2078856.2078859

[12] F. Moller and T. Crick. 2016. A National Engagement Model for Developing Computer Science Education in Wales. In The 9th International Conference on Informatics in Schools,. Munster, Germany, 1-13.

[13] Carsten Schulte, Malte Hornung, Sue Sentance, Valentina Dagiene, Tatjana Jevsikova, Neena Thota, Anna Eckerdal, and Anne-Kathrin Peters. 2012. Computer science at school/CS teacher education - Koli working-group report on $\mathrm{CS}$ at school. In International Conference on Computing Education Research, Koli Calling 2012. https://doi.org/10.1145/2401796.2401800

[14] Maciej M. Sysło and Anna Beata Kwiatkowska. 2015. Introducing a new computer science curriculum for all school levels in Poland. In Lecture Notes in Computer Science (including subseries Lecture Notes in Artificial Intelligence and Lecture Notes in Bioinformatics). https://doi.org/10.1007/978-3-319-25396-1\{_\}13

[15] The Royal Society. 2012. Shut down or restart? The way forward for computing in UK schools. Technical Report. London. https://royalsociety.org/ /media/ education/computing-in-schools/2012-01-12-computing-in-schools.pdf

[16] The Royal Society. 2017. After the reboot: Computing education in UK schools. Technical Report. The Royal Society, London, United Kingdom. 1-116 pages. royalsociety.org/computing-education

[17] Mary Webb, Niki Davis, Tim Bell, Yaacov J Katz, Nicholas Reynolds, Dianne P Chambers, and Maciej M Sysło. 2017. Computer science in K-12 school curricula of the 2lst century: Why, what and when? Education and Information Technologies 22, 2 (3 2017), 445-468. https://doi.org/10.1007/s10639-016-9493-x 